\section{Apperceptive Visual Agnosia}

\author{
John E. Mendoza
}

Department of Psychiatry and Neuroscience, Tulane Medical School and SE Louisiana Veterans Healthcare System, New Orleans, LA, USA

\section{Definition}

Inability or marked difficulty in visually identifying an object or picture of an object as a result of impaired perceptual abilities. In apperceptive agnosia, in addition to problems in the visual identification of an object, patients show impairment in reproducing (e.g., by drawing) the object or image and even matching the item to a similar one within a visual array. This contrasts with associative visual agnosia in which identification may also be impaired but the patient can usually render a reasonable representation (e.g., a drawing or graphomotor copy) of the object that cannot be visually identified and can visually match it to a sample. Apperceptive visual agnosia likely results from a defect in the secondary association areas of the visual cortex and is usually found in patients who complain of general loss or reduction in visual acuity.

\section{Cross-References}

Associative Visual Agnosia

\section{References and Readings}

Bauer, R. M., \& Demery, J. A. (2003). Agnosia. In K. Heilman \& E. Valenstein (Eds.), Clinical neuropsychology (4th ed., pp. 236-295). New York: Oxford University Press.

DeRenzi, E., \& Spinnler, H. (1966). Visual recognition in patients with unilateral cerebral disease. Journal of Nervous and Mental Disease, 142, 513-525.

DeRenzi, E., Scotti, G., \& Spinnler, H. (1969). Perceptual and associative disorders of visual recognition. Relationship to the side of the cerebral lesion. Neurology, 19, 634-642. 